\title{
When do relative prices matter for measuring income inequality? The case of food prices in Mozambique
}

\author{
Channing Arndt • Sam Jones • Vincenzo Salvucci
}

Received: 4 May 2014 / Accepted: 27 February 2015 / Published online: 21 March 2015

(C) Springer Science+Business Media New York 2015

\begin{abstract}
Changes in relative prices of commodities consumed in different shares across income groups can be expected to alter real income differentials between these groups. Using Mozambican household budget survey and price data from 2002/03 and 2008/09, we show that once relative price increases are accounted for, inequality of real consumption increases substantially. We obtain this result by constructing a price deflator that reflects divergent price dynamics of different product categories. Since the main factors driving this result prevail in other developing countries, it is likely that inequality may be underestimated elsewhere.
\end{abstract}

Keywords Relative price changes $\cdot$ Price index $\cdot$ Income inequality $\cdot$ Mozambique

\section{Introduction}

The observation that if "the prices of 'luxuries' and 'necessities' move differently, then different groups are differently affected" (Muellbauer 1974, p. 32) is far from new but

Electronic supplementary material The online version of this article

(doi:10.1007/s10888-015-9303-5) contains supplementary material, which is available to authorized users.

C. Arndt

World Institute for Development Economics Research,

United Nations University, Helsinki, Finland

e-mail: Channing@wider.unu.edu

S. Jones $(\varangle) \cdot$ V. Salvucci

Development Economics Research Group, Department of Economics,

University of Copenhagen, Copenhagen, Denmark

e-mail: sam.jones@econ.ku.dk

V. Salvucci

e-mail: Vincenzo.Salvucci@econ.ku.dk 
remains under-explored. Existing research on economic inequality in developing countries usually pays little attention to changes in relative prices between basic products and nonnecessities. At most, aggregate geographic price indexes are employed to deflate nominal income, implicitly assuming all agents in each region consume the same basket of goods on average. ${ }^{1}$ This assumption is not innocuous.

Both in advanced and developing countries, rich and poor households live in similar locations yet consume different baskets of goods. Where the prices of goods in their respective baskets follow very different dynamics, application of a single aggregate price index to deflate nominal incomes can yield a misleading view of inequality of real income. Put differently, in addition to spatial heterogeneity in prices, we should be aware of heterogeneity driven by differences in spending patterns along the income distribution combined with shifting relative prices.

In this paper, we explicitly consider the impact of differential price dynamics on inequality of real income. Rather than apply a single price deflator across the income distribution, we construct an alternative deflator that is sensitive to differences in household expenditure on different goods. This new deflator can be constructed at an arbitrary level of specificity. However, for both clarity and practical reasons, we focus on price trends in three broad product categories, namely: (i) basic or "core" foods; (ii) "non-core" foods; and (iii) other goods (non-food expenses).

We apply this method to the case of Mozambique over a period of substantial changes in relative prices. Our alternative deflator indicates large differences between inequality of nominal and real income. ${ }^{2}$ In particular, inequality of real income in Mozambique is shown to be substantially higher as a result of an upward trend in basic commodity prices that occurred around 2000, which was strongly expressed in the food and fuel price crisis of 2007-2009. As many developing and food-importing countries share the drivers of this result, it is possible that the implications for inequality of the rise in the relative price of basic goods in general, and the food and fuel price crisis of 2007-2009 in particular, have been underestimated in other countries. ${ }^{3}$

The remainder of this article is structured as follows. Section 2 briefly presents the motivation. Section 3 describes the general methodology used to construct alternative price indexes. Our approach represents an enhancement of the method due to Günther and Grimm (2007) since it does not depend on any ex ante ranking of households by nominal income. Section 4 applies our approach to the case of Mozambique. It discusses price dynamics over the 2007-2009 food price crisis, the data used, and the specific derivation of our new price indexes. It also presents our results concerning inequality for Mozambique, including an analysis at the sub-national level. Section 5 concludes, noting that greater attention to relative price shifts across the income distribution is merited when studying inequality.

\footnotetext{
${ }^{1}$ Noted exceptions that consider the importance of relative prices changes for different population groups are Muellbauer (1974), Amble and Stewart (1994), Garner et al. (1996), Hagemann (1982), Cage et al. (2002), Crawford and Smith (2002), Leicester et al. (2008), among others.

${ }^{2}$ In the application to Mozambique, we use survey-based estimates of total consumption to proxy for permanent income.

${ }^{3}$ For example, Oosthuizen (2013) finds evidence for inequality increases in South Africa due to relative price shifts.
} 


\section{Motivation}

In order to obtain measures of real expenditure, nominal expenditures are usually deflated by a national or region-specific consumer price index (CPI). Since metrics of income inequality are (typically) scale-invariant, it follows there should be no difference between measures of inequality of nominal and real income when a single aggregate CPI is used to deflate nominal observations. However, there are established drawbacks to relying on a highly aggregate price index for the purposes of measuring welfare. For example, consumption patterns of poor people may vary substantially across space. Because consumption baskets used to measure absolute poverty in developing countries ideally reflect consumption patterns of the poor (Deaton 1998; Ravallion and Bidani 1994), steps are increasingly taken to account for these variations (Arndt and Simler 2010). Indeed, under the costs of basic needs approach, failure to account for the specific consumption patterns of the poor can lead to erroneous conclusions about poverty levels and trends (Tarp et al. 2002; Günther and Grimm 2007).

The point highlighted by Muellbauer (1974) is that, in addition to spatial heterogeneity, the welfare implications of changes in relative prices can vary according to one's position along the income (consumption) distribution. Even within relatively small geographic areas, households frequently consume substantially different types of goods in different proportions (on a per capita basis). Consequently, neither use of a national/regional price deflator nor a focus on consumption patterns of a specific group (e.g., the poor) is likely to reflect relative price differences across the distribution of income. Consequently, application of such price deflators can be misleading when we wish to analyse developments in inequality of real income.

To fix ideas, the remainder of this section provides an analytical example of how income-specific relative price changes (i.e., differences in costs of living along the income distribution) can drive a wedge between inequality of nominal and real incomes. To do so, presume that the cost of living (average price index) faced by each household is a function of her level of income (consumption), as follows:

$$
P_{j}\left(y_{j}\right)=\left[1-\alpha\left(\bar{y} / y_{j}-1\right)\right]^{-1}=\frac{y_{j}}{y_{j}+\alpha\left(y_{j}-\bar{y}\right)}
$$

where $j$ is the household and $y_{j}$ its income. This says that for positive values of $\alpha$, observations with $y_{j}$ that are above (below) the mean correspond to a price index less than (greater than) one. In cases where food prices are consistently higher (or rising faster) than prices of all other goods, we expect $\alpha>0$ by Engel's Law.

This particular specification of the price index is useful on two counts. First, it provides a simple expression for real income $(\tilde{y})$ as a function of nominal income and the incomegradient of the cost of living $(\alpha)$ - i.e., omitting household subscripts we have: $\tilde{y}=y / p=$ $y+\alpha(y-\bar{y})$. Continuing to assume $\alpha>0$, it follows that: $\tilde{y}>y$ if $y>\bar{y}$ and vice versa, implying that positive values of $\alpha$ induce greater dispersion in real versus nominal income. Second, our price index provides a natural interpretation of $\alpha$. Specifically, noting that

$$
\mathrm{E}(\tilde{y})=\mathrm{E}(\mathrm{y}), \operatorname{Var}(\tilde{y})=(1+\alpha)^{2} \operatorname{Var}(\mathrm{y})
$$

we can interpret $\alpha$ as the percentage point difference in the coefficient of variation of real compared to nominal income. Focussing on the question at hand, a closed form expression 
for the effect of alternative values of $\alpha$ on inequality of real income can be derived for the Gini coefficient. As shown by Ogwang (2000), the Gini can be calculated from estimates of a linear regression of the income measure on the associated household income ranks (denoted $i$ ). That is, inequality of nominal income is given by:

$$
\operatorname{Gini}(y)=\frac{n^{2}-1}{6 n} \frac{\mathrm{E}[\tilde{i}(y-\bar{y})]}{\mathrm{E}\left(\tilde{i}^{2}\right) \mathrm{E}(y)}=\frac{n^{2}-1}{6 n} \frac{\hat{\beta}_{y}}{\bar{y}}
$$

where $\hat{\beta}_{y}$ is taken from estimates of the linear regression model: $y=\lambda+\beta i+\varepsilon$; and $\tilde{i}=i-\bar{i}$. To derive an expression for the partial derivative of the real income Gini to $\alpha$, note that by virtue of our particular specification of the price index, the rank ordering of agents is independent of the choice of $\alpha$. In fact, comparing the corresponding expression for Gini $(\tilde{y})$ to Eq. 3, the only element that differs is the numerator of the estimate for $\hat{\beta}_{\tilde{y}}$ (here calculated using real income as the dependent variable). Examining this term we have:

$$
\begin{aligned}
\hat{\beta}_{\tilde{y}} & =\frac{\mathrm{E}[\tilde{i}(\tilde{y}-\overline{\tilde{y}})]}{\mathrm{E}\left(\tilde{i}^{2}\right)}=\frac{\mathrm{E}[\tilde{i}(1+\alpha)(y-\bar{y}]}{\mathrm{E}\left(\tilde{i}^{2}\right)} \\
& =\frac{(1+\alpha) \mathrm{E}[\tilde{i}(y-\tilde{y})]}{\mathrm{E}\left(\tilde{i}^{2}\right)}=(1+\alpha) \hat{\beta}_{y}
\end{aligned}
$$

It follows that the partial derivative of inequality of real income with respect $\alpha$ simply is:

$$
\partial \operatorname{Gini}(\tilde{y}) / \partial \alpha=\frac{n^{2}-1}{6 n} \frac{\hat{\beta}}{\bar{y}}=\operatorname{Gini}(y)
$$

This says that if application of our income-specific price deflator generates a $10 \%$ increase in the coefficient of variation in real income relative to that of nominal income (which corresponds to setting $\alpha=0.1$ ), the corresponding Gini coefficient also will rise by $10 \%$. So, in this very stylized case, the sensitivity of inequality to changes in the price gradient is a function of initial income inequality and (trivially) the slope of the income gradient of the cost of living.

It merits comment that this result is a direct corollary of Milanovic's (1997) observation that the Gini coefficient is a product of three elements: the coefficient of variation, the correlation between income and its ranks, and a constant. In this example, only the first of these terms varies with changes in our price index; thus we find a one-to-one relation between changes in $\alpha$ and changes in the real income Gini coefficient.

\section{Methodology}

Following the above, a price deflator is required that reflects differences in relative prices along the income distribution in a given location. An approach used in previous studies has been to compute a (national) consumer price index for each percentile group of the nominal income distribution (e.g., Günther and Grimm 2007). A drawback of this method is that, in contrast to the stylized example of Section 2, ranking households according to their nominal incomes may not correspond to their ranking by real income, where the latter is calculated from a household-specific 'true' cost of living index. A priori, it is not unreasonable to expect that households with the same nominal per capita income may have very different expenditure shares over alternative goods, meaning that their effective cost of living differs.

To account for this, we derive a consumption deflator based on the observed (chosen) expenditure structure of households. This avoids the problem of relying on the overall value 
of nominal consumption to construct the price index and directly allows for different relative price movements across categories of expenditure. At the most generic level, therefore, a household-specific price index (defined at time $t$, subscript not shown) can be defined as:

$$
h_{j}=\sum_{k \in K} \frac{x_{j k} p_{k}}{\sum_{k^{\prime} \in K} x_{j k^{\prime}}}=\sum_{k \in K} \frac{x_{j k} p_{k}}{\sum_{k^{\prime} \in K} x_{j k^{\prime}}}=\sum_{k \in K} w_{j k} p_{k}
$$

where $k$ is a member of the set of all goods available in the economy $(K) ; p_{k}$ is the observed price index of good $k$ (which takes a value of one in the base year for all goods); and $w_{j k}=$ $x_{j k} / \sum_{k^{\prime} \in K} x_{j k^{\prime}}$ is the share of household $j$ 's expenditure on good $k{ }^{4}$

Theoretically, there is no reason why the vector $h$ cannot be used to calculate moments of the 'true' real income distribution. In practical terms, however, it is often not possible to implement (6) at the product-specific level. Household budget survey information is never perfect and effective prices cannot be estimated with confidence for all goods in the economy - i.e., there are many goods with few or no price observations or with vast variations in quality, which would make direct estimates of Eq. 6 unreliable. Therefore, it is more practical to approximate (6) by considering shares of expenditure on broader product categories. ${ }^{5}$ This is the route adopted in our application to Mozambique, to which we now turn.

\section{Application to Mozambique}

\subsection{Background}

Over the period 2007-2009, the price of staple foods and fuel increased dramatically on international markets relative to other consumption goods (see Online Supplementary Material Fig. A1, panel a). These increases were quickly passed on to domestic prices in many developing and developed countries (Dillon and Barrett 2013; Arndt et al. 2008). The case of Mozambique is of interest because the price upsurge of 2007-2009 was captured in a detailed budget survey that was in the field from September 2008 to August 2009. Using official price data from the capital city, Online Supplementary Material Fig. A1, panel (b), illustrates trends in food and non-food items in Mozambique over time. The two trends diverge substantially in the later period shown. This almost certainly reflects the effect of the international food price upsurge on food products in Mozambique. In particular, from the end of 2006, the price index for non-food products is lower than the overall CPI and substantially lower than the food price index.

Importantly, Mozambique is a net importer of staple foods such as wheat and rice. These items constitute significant budget shares of lower income households, particularly in urban

\footnotetext{
${ }^{4}$ The price index presented corresponds neither to a Laspeyeres nor to a Paasche index (for detailed discussions of alternative cost of living indices, see Schultze and Mackie 2002). For various reasons, most national statistical agencies, including the Mozambican one, prefer to use the Laspeyres index (INE 2002). This differs from the index presented as it uses base-year and not current-year shares. However, the results of this paper are essentially unchanged when a Laspeyres index is used (not shown).

${ }^{5}$ Future applications of this method may not face the same data restrictions and more disaggregate analysis may be possible.
} 
areas. ${ }^{6}$ In addition, adverse weather conditions depressed agricultural production levels for the 2008 harvest, particularly in the North and Centre (Arndt et al. 2012). As documented by Hanlon (2009), food and fuel price rises over 2007-2009 lay behind outbursts of social unrest in urban areas in this period. In light of the discussion in previous sections, Mozambique provides a test case of the hypothesis that inequality of nominal and real incomes differ materially once differential relative price trends are captured. Moreover, as in other southern African countries, the degree of inequality in Mozambique is comparatively high by international standards and observed consumption patterns differ markedly between rich and poor.

\subsection{Data}

The primary data used in this study are a series of microeconomic household budget surveys. We use the 2002/03 Inquérito aos Agregados Familiares (IAF02) and the 2008/09 Inquérito aos Orçamentos Familiares 2008/09 (IOF08). The IOF08 was conducted from September 2008 to August 2009, while the IAF02 was conducted from July 2002 to June 2003. The surveys have a stratified structure with three main design steps: (i) definition of strata and primary sampling units (PSUs); (ii) random selection of PSUs within each stratum; and (iii) random selection of households within each PSU. Nine households were selected in each rural PSU and twelve in each urban PSU. Twenty-one strata were constructed, one for each urban/rural area of the 10 provinces of Mozambique, plus the capital Maputo City, which does not have a rural area (MPF 2004). The final sample size of the IAF02 amounts to 8,727 households: 4,020 urban households and 4,707 rural households. The IOF08 has a sample size of 10,832 households, divided into 5,223 urban households and 5,609 rural households. Both surveys are representative at the national, regional (North, Centre, South), provincial, and urban/rural level, and by survey quarter.

The surveys collected information on the general characteristics of individuals and households, as well as information on daily consumption, monthly consumption, possession of durable goods, transfers, and gifts. Total household consumption (expenditure) is derived from the surveys following the official methodology described in MPD/DNEAP (2010). The total value includes food and non-food consumption, which not only encompass market purchases but also self-produced goods, imputed rent of housing, the use value of durable goods and consumption of goods via payments in-kind and transfers. The total value of consumption is calculated for the household as a whole. However, for the purposes of analysis these totals are normalized by the number of household members, giving a per capita (mean) value. ${ }^{7}$

Details and supplementary information for the IAF02 can be found in MPF (2004), while for the IOF08 it can be found in INE (2010) and MPD/DNEAP (2010). It is important to point out that Mozambique is a large country with relatively weak road infrastructure and low (rural) population density. As a result, price analysis on the budget survey data is undertaken separately for 13 geographical regions. These constitute spatial domains that largely correspond to distinct agro-ecological conditions and, therefore, potentially large

\footnotetext{
${ }^{6}$ The urban budget share for rice and wheat in urban areas amounts to $9.6 \%$ and $5.1 \%$, respectively. However, for poor urban households, the budget shares rise to $11.9 \%$ for rice and $6.6 \%$ for wheat.

${ }^{7}$ Unlike some other developing countries, no equivalence scale is used to assign different weights to household members (MPD/DNEAP 2010). This choice has no material impact on the results in focus here.
} 
differences in the supply/demand of different food items. This issue is taken up further below.

As described in MPD/DNEAP (2010), food and total poverty lines are constructed from the surveys for each spatial domain. These lines can be used as consumption deflators that reflect the expenditure patterns of poor households across space. The other main source of price information is the official disaggregated data used to track consumer prices. Specifically, Mozambique's official national and regional CPIs are estimated from productspecific monthly price data over the period 2003-2009 collected in three urban areas (Nampula, Beira and Maputo located in the North, Centre, and South respectively). This base data can be used to construct bespoke price indexes for different product groups (see further below). Both the budget surveys and the price index series are collected by the National Institute of Statistics (INE).

\subsection{Household-specific price indexes}

Existing price indexes taken from CPI data or the household surveys (poverty lines and their ratios) do not vary within specified geographical locations at each point in time. That is, they ignore local differences in effective living costs along the income distribution. Thus, in order to construct category- and household-specific price indexes for Mozambique, we combine the detailed product-specific CPI data with household expenditure data from the IAF02 and IOF08 surveys. This combination is necessary because the budget surveys only provide detailed data on prices (as distinct from expenditures) for a relatively limited range of food products. These are sufficient to develop and price a cost of basic needs poverty line, but they do not adequately capture the full range of prices for other goods as required here.

We proceed in three steps. First, based on the household data, we divide total household nominal expenditure into three main categories. As noted previously, the motivation for this is that reliable price data is not available for the full range of products in each location. The expenditure categories are: (i) basic or "core" foods; (ii) "non-core" foods; and (iii) all other non-food items. Food items are distinguished between core and non-core categories according to their respective shares of total expenditures. Specifically, in each of the 13 spatial domains we sort food products by their share of total food expenditures. Foods that appear below a cumulative cut-off of $75 \%$ of total food expenditure are excluded from the preliminary list in each domain. In turn, core foods are defined as those food items that appear on the retained lists of at least three spatial domains. ${ }^{8}$

Second, a different price index is adopted for each product category in each spatial domain. ${ }^{9}$ For core foods we use the ratio of food poverty lines calculated from the IOF08 and IAF02 surveys. This effectively represents core food inflation that occurred between the two periods, taking 2002/03 as the base. For the two remaining categories, we create bespoke indexes from the CPI data that correspond to other foods (i.e., all foods excluding core food items) and to all other (non-food) items. Since the CPI data is only available in

\footnotetext{
${ }^{8}$ The list of core food products includes: mackerel, poultry, maize flour, white maize, beef, brown sugar, butter bean, dried fish, sawfish, cacana leaves, cowpea, wheat bread, groundnut, coco, squash leaves, tomato, rice, cassava flour, fresh cassava, and sunflower oil. The results presented in the next sections are robust to different cut-offs.

${ }^{9}$ We recognize that it would be preferable to use location- and product-specific prices here. However, this is not feasible due to the limited nature of available price data.
} 
Table 1 Alternative (mean) price indexes by location

\begin{tabular}{|c|c|c|c|c|c|}
\hline & \multicolumn{3}{|c|}{ Category-specific indexes } & \multirow{3}{*}{$\begin{array}{l}\text { CPI } \\
\text { IV }\end{array}$} & \multirow{3}{*}{$\begin{array}{l}\text { PLR } \\
\mathrm{V}\end{array}$} \\
\hline & Core & Non-core & Non-food & & \\
\hline & I & II & III & & \\
\hline North & 238.5 & 212.3 & 150.5 & 190.1 & 232.0 \\
\hline Centre & 258.8 & 187.5 & 154.7 & 171.3 & 258.3 \\
\hline South & 183.4 & 171.6 & 145.7 & 165.0 & 183.8 \\
\hline Urban & 203.3 & 188.0 & 149.8 & 174.0 & 202.8 \\
\hline Rural & 247.5 & 193.6 & 151.8 & 176.8 & 244.4 \\
\hline National & 234.1 & 191.9 & 151.2 & 176.0 & 231.8 \\
\hline
\end{tabular}

Note: all indexes refer to the period 2008/09, taking as a base year 2002/03; category-specific price indexes refer to core food, non-core food and non-food items; index in column I is calculated from household surveys; indexes in columns II and III are calculated from non-food items in the CPI; column IV is the aggregate CPI; column V is the ratio of poverty lines (PLR) also estimated from the household surveys (IOF08/IOF02); all calculations are population-weighted.

three locations (regions), individual households are allocated to their 'nearest' available CPI data point. ${ }^{10}$

Third, a household-specific price index (HPI) is calculated as the sum of the product of each category-specific (and spatial domain-specific) price index and the observed share of household expenditure. The resulting HPI is a weighted average of the three categoryspecific price indexes, which is just a simplified version of Eq. 6. Specifically, for household $j$ in spatial domain $d$ we have:

$$
\operatorname{HPI}_{d j 1}=\sum_{i \in\{\text { core,non-core,other }\}} w_{d j i 1}\left(\frac{p_{d i 1}}{p_{d i 0}}\right)
$$

where $w_{d j i 1}$ represents the expenditure share of household $j$, located in domain $d$, on items in category $i$ in 2008/09 (time index $=1$ ); $p_{\text {dit }}$ represents the estimated price index of goods in category $i$ in spatial domain $d$ at time $t$; and time index 0 corresponds to the base year, 2002/03.

\subsection{Results for price indexes}

Table 1 compares the levels of alternative price indexes in different regions (area of residence), as well as for the country as a whole. All indexes are reported for the period 2008/09 taking 2002/03 as the base period. ${ }^{11}$ Columns I to III present the category-specific price indexes used to adjust nominal consumption for the purposes of measurements of inequality of real income. Column I contains the core food index, which is derived from the food

\footnotetext{
${ }^{10}$ Specifically, households from the northern spatial domains are allocated to the CPI collected for Nampula city. Households from spatial domains in the central region are allocated to the CPI of the city of Beira; households from the southern spatial domains to CPI data from Maputo.

${ }^{11}$ More precisely, we take the last month of the surveys as our reference points: July 2003 is set equal to 100 while the price index for 2008/09 is taken from August 2009.
} 


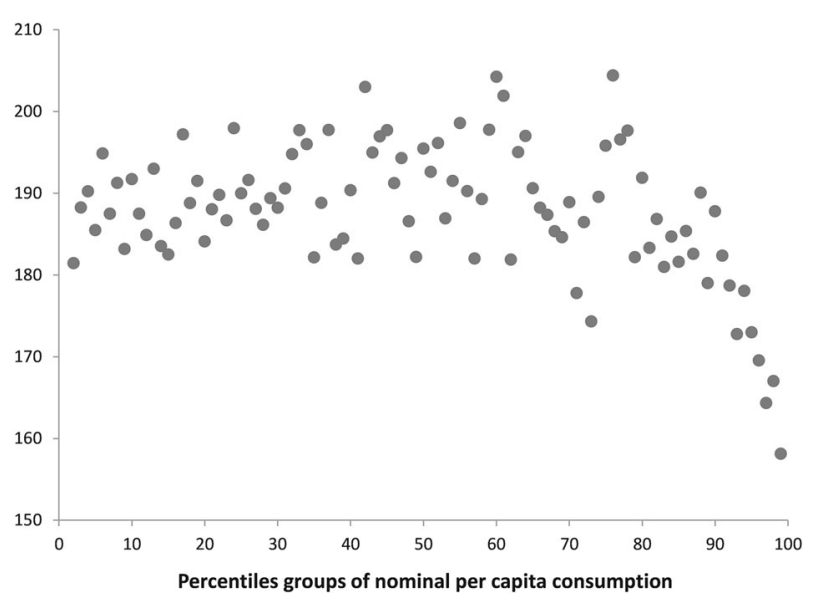

Fig. 1 Percentile group-specific price indexes of (spatially-adjusted) nominal per capita consumption. Note: Percentile group-specific price indexes were obtained computing the median of household-specific price indexes (HPIs) for each percentile group of spatially-adjusted nominal per capita consumption. The $1^{\text {st }}$ and $100^{\text {th }}$ percentile groups are excluded from the figure

poverty lines previously estimated from the household survey data; columns II and III represent the non-core food and non-food categories, calculated from the disaggregated CPI series. For comparison, column IV is the aggregate CPI; and column V is the full (food and non-food) poverty line ratio (PLR) from the two household surveys (IOF08/IOF02). ${ }^{12}$

The table confirms that prices of different product categories followed different dynamics over time. In particular, in all regions and areas of residence, the price index for core food is always higher than the price index for non-food. This corresponds to the tendencies outlined in Online Supplementary Material Fig. A1, panel b, where prices of core food products increased more rapidly than non-core foods and non-food items in particular.

Table A1 in the Online Supplementary Material reports aggregate expenditure shares by consumption quintile groups. As expected, we observe that poorer households devote a relatively larger share of total consumption to food products (especially core food products) compared to richer households (see also Online Supplementary Material Fig. A2). ${ }^{13}$ The lowest consuming quintile group allocates a smaller share of total consumption expenditure to core food and a higher share to non-food than the second lowest group. This reflects, in substantial measure, imputed values for owner-occupied housing. By design of the sample frame, every household in the sample lives in a dwelling, and a minimum value is ascribed to even the most basic dwelling. As all other expenditures decline, the share of this minimum value rises.

Putting this together, there is clear evidence that the cost of living has an income gradient. Thus, following (7), for each household we calculate the HPI which is a weighted sum of the category-specific price indexes (see Table 1) where the weights are their observed

\footnotetext{
${ }^{12}$ Since poverty line ratios are computed for each spatial domain $d$, the national, regional and urban/rural statistics presented are calculated by taking the population-weighted averages.

${ }^{13}$ In Mozambique almost $55 \%$ of the population was classified as consumption poor in 2008/09 (MPD/DNEAP 2010).
} 
Table 2 Metrics of consumption inequality applying alternative price deflators, without spatial adjustment:

\begin{tabular}{|c|c|c|c|c|c|c|c|c|}
\hline \multirow{4}{*}{$\begin{array}{l}\text { Deflator } \\
\text { Survey }\end{array}$} & \multicolumn{2}{|l|}{ I } & \multicolumn{2}{|l|}{ II } & \multicolumn{2}{|l|}{ III } & \multicolumn{2}{|l|}{ IV } \\
\hline & & \multicolumn{2}{|l|}{ None } & \multicolumn{2}{|l|}{ CPI } & \multicolumn{2}{|l|}{ HPI } \\
\hline & \multicolumn{2}{|c|}{$2002 / 03$} & \multicolumn{2}{|c|}{ 2008/09 } & \multicolumn{2}{|c|}{ 2008/09 } & \multicolumn{2}{|c|}{$2008 / 09$} \\
\hline & Gini & SE & Gini & SE & Gini & SE & Gini & SE \\
\hline North & 0.417 & $(0.022)$ & 0.424 & $(0.015)$ & 0.424 & $(0.015)$ & 0.454 & (0.017) \\
\hline Centre & 0.415 & $(0.010)$ & 0.405 & (0.009) & 0.405 & (0.009) & 0.432 & $(0.010)$ \\
\hline South & 0.538 & $(0.009)$ & 0.507 & $(0.009)$ & 0.507 & (0.009) & 0.526 & (0.009) \\
\hline Urban & 0.521 & $(0.011)$ & 0.506 & $(0.009)$ & 0.512 & $(0.009)$ & 0.537 & (0.009) \\
\hline Rural & 0.368 & $(0.007)$ & 0.377 & $(0.007)$ & 0.376 & $(0.007)$ & 0.398 & $(0.009)$ \\
\hline National & 0.477 & $(0.007)$ & 0.458 & $(0.006)$ & 0.463 & $(0.006)$ & 0.504 & $(0.007)$ \\
\hline
\end{tabular}

Note: the Gini indexes are computed from nominal per capita consumption measures for 2002/03 (column I) and 2008/09 (columns II to IV) applying alternative deflators; the CPI deflator is the region-specific official consumer price index; the HPI is our preferred household-specific index. SE: standard error

consumption shares by category (see summary indicators in Online Supplementary Material Table A1). This gradient is illustrated in Fig. 1, which plots the median HPI for each percentile group of nominal per capita consumption in 2008/09. It shows substantial differences in the deflator along the consumption distribution, particularly between the richest quintile and the rest. It follows that use of the HPI is likely to affect metrics of inequality.

\subsection{Inequality results}

For the final stage of analysis, we compare inequality metrics after applying alternative price deflators to nominal consumption, thereby yielding metrics of inequality in real consumption. Our main focus is the HPI (see Eq. 7); however, for comparison purposes, we also report alternative deflators. Table 2 shows Gini coefficients at national, regional and urban/rural levels without spatial price deflation. Column I reports inequality estimates from the base year (2002/03) for which all price indexes are set to 100, implying the inequality measures refer to nominal per capita consumption only. Column II is the corresponding measure of inequality of nominal per capita consumption in 2008/09 (no deflator applied). ${ }^{14}$ Column III applies the CPI deflator (which is constant across all household in each region but varies across regions: North, Centre and South) to nominal consumption in 2008/09; and column IV applies the HPI, which is our preferred household-specific index (see (7)).

A potential concern when dealing with nominal consumption values in Mozambique is that price levels differ widely between regions, as well as between urban and rural areas (Cirera and Arndt 2008; Tostão and Brorsen 2005; MPF 2004; MPD/DNEAP 2010). That is, the Mozambican Metical does not have the same purchasing power in all locations. This concern is not addressed in Eq. 7 since the focus of deflation there is only on temporal price changes within each spatial domain (for each household), meaning no adjustment is made for differences in price levels between domains. As already noted, one way to deal with this would be to construct a single price index for each category from observed product-specific

\footnotetext{
${ }^{14}$ Results applying no deflator are effectively the same as those from applying a single national deflator.
} 
prices that captures spatial and expenditure share differences. ${ }^{15}$ However, both the quality of the available price data and the fact that we use price data from different sources (with different geographical coverage) precludes this option. Hence, to address this and consistent with official inequality estimates for Mozambique, we scale nominal consumption by a separate spatial price index that captures internal price differences between locations at a given point in time (MPD/DNEAP 2010) This index is calculated from the food items observed in the household surveys in each of the 13 spatial domains. ${ }^{16}$ After this spatial adjustment, the HPI can be applied. However, to avoid double counting of spatial differences, we use a modified version of the HPI. This uses as a temporal deflator the national (i.e., weighted average) food poverty line ratio for core food and the national categoryspecific CPI for non-core food and non-food. ${ }^{17}$ Thus, the metric of spatially-adjusted real consumption that is sensitive to household-specific consumption choices is given by:

$$
\tilde{x}_{d j t}=x_{d j t} /\left(s_{d t} \times \overline{H P I}_{j t}\right)=x_{d j t} / \mathrm{HPI}_{d j t}^{*}
$$

where $s_{d t}$ is the spatial deflator for a given location and period (the population-weighted average of $s_{d t}$ is normalized to one). ${ }^{18}$ Table 3 shows the set of Gini coefficients computed taking such spatial adjustments into account, meaning that in all columns a spatial price index (SPI) is used.

What do we learn from these results? Comparison of column I in Tables 2 and 3 with the remaining columns in each table illustrates the estimated impact on inequality of using alternative deflators. In both Tables 2 and 3, comparison of the HPI-based inequality metrics for 2008/09 with the alternatives for the same period isolates the impact of considering the expenditure structure of households when relative prices change. We find that careful consideration of such changes in the relative prices of core food, non-core food, and non-food materially increases estimates of inequality of real consumption in all cases. For Mozambique, the implications of applying the HPI are strongest in the non-spatially deflated case. This occurs because of a correlation between welfare levels and spatial differences in inflation rates over the period considered, meaning that spatial deflation effectively captures some of the variation in relative prices across the income distribution. For the non-spatially deflated measures presented in Table 2, the increment to inequality at the national level is approximately 4.6 Gini points when comparing columns II and IV. ${ }^{19}$

Turning to Table 3, the application of the SPI reduces the level of inequality as measured by the Gini index at all geographical levels relative to Table 2 . This is principally because the SPIs account for higher living costs in urban zones. When using spatially deflated

\footnotetext{
${ }^{15}$ We thank an anonymous reviewer for pointing this out.

16 The spatial price index is calculated using the consumption bundle in each spatial domain, which reflects the consumption patterns of the poor in that region, and the cost of the bundle calculated using the prices prevailing in that region. These consumption bundles usually contain between 20 and 30 food items for each spatial domain, as they account for $95 \%$ of calculated per capita calorie needs in each spatial domain (MPF 2004; MPD/DNEAP 2010).

${ }^{17}$ This is necessary since the act of scaling consumption in 2002/03 and 2008/09 by spatial price indexes in each year respectively (see (8)) will capture some degree of differences in temporal dynamics between locations. Thanks are due to an anonymous reviewer for emphasizing this point.

${ }^{18}$ We find essentially the same analytical results by holding the spatial price deflator constant over time (at $2002 / 03$ or 2008/09 values) in all price index calculations and applying the unmodified HDI. Results are available on request.

${ }^{19}$ Tables 3 and 4 omit a column for the CPI deflator since this should be held constant nationally after taking into account the period-specific SPIs (as per the logic for the HPI*). As such, it becomes superfluous.
} 
Table 3 Metrics of consumption inequality applying alternative price deflators, with spatial adjustment

\begin{tabular}{|c|c|c|c|c|c|c|}
\hline \multirow{4}{*}{$\begin{array}{l}\text { Deflator } \\
\text { Survey }\end{array}$} & & \multicolumn{2}{|l|}{ II } & \multicolumn{2}{|l|}{ III } \\
\hline & & \multicolumn{2}{|l|}{ SPI } & \multicolumn{2}{|l|}{ HPI* } \\
\hline & \multicolumn{2}{|c|}{$2002 / 03$} & \multicolumn{2}{|c|}{$2008 / 09$} & \multicolumn{2}{|c|}{$2008 / 09$} \\
\hline & Gini & SE & Gini & SE & Gini & SE \\
\hline North & 0.385 & $(0.017)$ & 0.411 & $(0.015)$ & 0.434 & $(0.017)$ \\
\hline Centre & 0.393 & (0.009) & 0.381 & (0.009) & 0.397 & $(0.010)$ \\
\hline South & 0.475 & (0.009) & 0.456 & $(0.008)$ & 0.487 & $(0.008)$ \\
\hline Urban & 0.479 & $(0.012)$ & 0.481 & $(0.011)$ & 0.513 & $(0.012)$ \\
\hline Rural & 0.371 & (0.007) & 0.367 & $(0.007)$ & 0.378 & $(0.009)$ \\
\hline National & 0.415 & $(0.007)$ & 0.414 & $(0.007)$ & 0.440 & $(0.008)$ \\
\hline
\end{tabular}

Note: the Gini indexes are computed from nominal per capita consumption measures for 2002/03 (column I) and 2008/09 (columns II and III) applying alternative deflators. The spatial adjustment applied involves dividing nominal per capita consumption by a spatial domain-specific spatial price index computed from the household surveys. To avoid double counting of spatial differences in the HPI, we use a modified version of the HPI in column III that relies upon national measures of inflation for the three components of the HPI: core food, non-core food, and non-food. SE: standard error

consumption, the Gini index is about 2.6 percentage points higher at the national level when comparing the HPI* with the official estimate for 2008/09 (shown in column II, Table 3). Hence, rather than finding a minor decline in inequality between 2002/03 and 2008/09 (see columns I and II of Table 3), application of the HPI* now produces a statistically significant increase.

Increases of this magnitude are economically meaningful, being roughly equal to the difference in Gini coefficients between relatively less unequal African countries like Mauritius, or Seychelles, and countries like Uganda or Zimbabwe, where income inequality represents a more pressing concern (Ssewanyana et al. 2004, 2012; World Bank 2012; Dashwood 2002; Manjengwa et al. 2012). ${ }^{20}$ Put differently, the same impact on the Gini index is slightly larger than the reduction in inequality experienced by Latin American countries between the late 1990s and the mid-2000s (Gasparini et al. 2011). It is also larger than the much-discussed rise in inequality observed in the US between the early 1990s and the late 2000s (OECD 2014).

Our results are not sensitive to the particular measure of inequality used. Panel (a) of Table 4 reports results for the Theil index, obtained from (spatially-adjusted) per capita consumption for 2002/03 and 2008/09, at national, urban/rural, and regional levels. Inequality of real consumption for 2008/09 is uniformly largest when the HPI* is used to deflate nominal consumption. The Theil index also permits a decomposition of the inequality measure into between- and within-components. This allows us to study whether the overall inequality measure depends more on the inequality that exists between selected groups, or instead it is due to the inequality within each location (group). We find that both at rural/urban and regional level, the bulk of existing inequality is due to within-group inequality. The betweengroup component contributes less than 10 percent for all the deflators applied. The high

\footnotetext{
${ }^{20}$ The Gini index is 38.8 for Mauritius; 39.9 for Seychelles; 42.3 for Uganda and Zimbabwe (UNU-WIDER 2014).
} 
Table 4 Inequality metrics, using spatially-adjusted consumption

\begin{tabular}{|c|c|c|c|c|c|c|}
\hline \multirow{4}{*}{$\begin{array}{l}\text { Deflator } \\
\text { Survey }\end{array}$} & & \multicolumn{2}{|l|}{ II } & \multicolumn{2}{|l|}{ III } \\
\hline & & \multicolumn{2}{|l|}{ SPI } & \multicolumn{2}{|l|}{ HPI* } \\
\hline & \multicolumn{2}{|l|}{$2002 / 03$} & \multicolumn{2}{|l|}{ 2008/09 } & \multicolumn{2}{|l|}{ 2008/09 } \\
\hline & Metric & SE & Metric & SE & Metric & SE \\
\hline \multicolumn{7}{|l|}{ (a) Theil index: } \\
\hline North & 0.346 & $(0.053)$ & 0.379 & $(0.044)$ & 0.448 & $(0.056)$ \\
\hline Centre & 0.309 & $(0.023)$ & 0.279 & $(0.022)$ & 0.320 & $(0.030)$ \\
\hline South & 0.495 & $(0.027)$ & 0.444 & $(0.021)$ & 0.517 & (0.024) \\
\hline Within-group & 0.364 & - & 0.358 & - & 0.421 & - \\
\hline Between-group & 0.003 & - & 0.007 & - & 0.011 & - \\
\hline Urban & 0.502 & $(0.039)$ & 0.500 & $(0.033)$ & 0.578 & (0.037) \\
\hline Rural & 0.267 & $(0.017)$ & 0.260 & $(0.021)$ & 0.291 & (0.029) \\
\hline Within-group & 0.358 & - & 0.352 & - & 0.408 & - \\
\hline Between-group & 0.009 & - & 0.014 & - & 0.024 & - \\
\hline National & 0.367 & $(0.020)$ & 0.366 & $(0.020)$ & 0.432 & $(0.025)$ \\
\hline \multicolumn{7}{|c|}{ (b) Percentile ratio (p90/p10): } \\
\hline North & 4.590 & $(0.249)$ & 5.266 & $(0.214)$ & 5.496 & (0.209) \\
\hline Centre & 5.405 & $(0.257)$ & 5.320 & (0.198) & 5.276 & (0.197) \\
\hline South & 6.817 & $(0.299)$ & 6.163 & $(0.291)$ & 6.768 & $(0.354)$ \\
\hline Urban & 6.825 & $(0.380)$ & 7.003 & $(0.274)$ & 7.814 & $(0.300)$ \\
\hline Rural & 5.035 & $(0.168)$ & 5.100 & $(0.150)$ & 5.042 & $(0.150)$ \\
\hline National & 5.566 & $(0.160)$ & 5.556 & $(0.129)$ & 5.775 & $(0.130)$ \\
\hline \multicolumn{7}{|l|}{ (c) Palma index: } \\
\hline North & 1.743 & $(0.155)$ & 1.982 & (0.154) & 2.218 & $(0.195)$ \\
\hline Centre & 1.801 & $(0.090)$ & 1.674 & $(0.081)$ & 1.837 & $(0.102)$ \\
\hline South & 2.730 & $(0.123)$ & 2.493 & $(0.102)$ & 2.935 & $(0.126)$ \\
\hline Urban & 2.786 & $(0.173)$ & 2.855 & $(0.167)$ & 3.359 & $(0.204)$ \\
\hline Rural & 1.603 & $(0.063)$ & 1.536 & $(0.063)$ & 1.666 & (0.079) \\
\hline National & 2.024 & $(0.073)$ & 2.016 & $(0.072)$ & 2.297 & (0.091) \\
\hline
\end{tabular}

Note: the inequality metrics are obtained from spatially adjusted nominal per capita consumption measures for 2002/03 (column I) and 2008/09 (columns II and III) applying alternative deflators. The percentile ratio p90/p10 is computed by taking the value of consumption at the 90 th percentile of the consumption distribution, divided by the value of consumption at the 10th percentile of the distribution. The Palma index corresponds to the ratio of the share of consumption held by the top 10 percent of the population and the share of consumption held by the bottom 40 percent.

within-group contribution shows that inequality between individuals in each region/area of residence is predominant.

Panel (b) of Table 4 presents the percentile ratio p90/p10, which is computed by dividing (spatially-adjusted) real consumption at the $90^{\text {th }}$ percentile of its distribution by real consumption at the $10^{\text {th }}$ percentile. A higher number can be interpreted as representing greater inequality - e.g., a value of five indicates that consumption at the $90^{\text {th }}$ percentile is five times higher than consumption at the $10^{\text {th }}$ percentile. This metric picks up a substantial increase 
in inequality in urban areas and the South when the HPI* is used. Similar results hold when the Palma index is employed (Table 4, panel c). ${ }^{21}$

Taking our results as a whole, a consistent finding is that inequality of real consumption in 2008/09 is largest when a HPI is used to deflate nominal consumption. At the national and urban levels, and for each of the three regions of the country, both the HDI-based Gini and Theil indexes are statistically different from their comparators. ${ }^{22}$ This underlines our thesis that taking due account of the expenditure structure of different income groups makes a significant difference to assessments of inequality. Finally, it merits comment that these results are robust to removal of extreme consumption values (e.g., dropping the $1^{\text {st }}$ and $100^{\text {th }}$ percentile groups).

\section{Conclusions}

This paper analysed how relative price changes of commodities consumed in different amounts by richer and poorer households influence metrics of consumption (income) inequality. Such relative price differences were particularly evident in developing and especially food-importing countries over the 2007-2009 period, characterized by food and fuel price crises. Income groups who relied more on basic (imported) foods were especially hit by the food price upsurge. Relative prices moved such that richer households consuming less basic foods as a share of total expenditure became better off in relative terms.

Using Mozambican household budget survey data from 2002/03 and 2008/09, we compared several inequality indexes based on alternative measures of real consumption. These were obtained using as deflators: (i) the official consumer price index, national or by region ( 3 regions); (ii) the poverty line from the last survey round (a poverty line in each of 13 spatial domains); and (iii) a composite household-specific price index based on categoryspecific price indexes for core food, non-core food, and non-food goods. We find that inequality of real consumption is substantially higher - by up to nearly five Gini points - when computed using a composite household-specific price index that is sensitive to differences in the share of these product groups in total household consumption.

There is little reason to believe that Mozambique is a unique or special case. Hence, our methodology is likely to have wider applications. In particular, inequality of real income may have been underestimated in other food-importing developing countries over the 2007 2009 food price crisis. The broader point is that greater attention to relative price movements at national and sub-nationals levels is merited in the analysis of trends in inequality of real income (consumption).

Acknowledgments We would like to thank the editor and anonymous referees for extremely helpful comments. Thanks also to staff of the Mozambican Ministry of Planning and Development and participants at the UNU-WIDER Inequality conference held in Helsinki in September 2014. Financial contributions from the governments of Denmark, Finland, Sweden, and the United Kingdom are gratefully acknowledged. All errors and omissions are our own.

\footnotetext{
${ }^{21}$ The Palma index thus is an alternative approach to measuring income inequality which is more sensitive than the Gini index to changes occurring at the top and at the bottom of the distribution (Palma 2011; Cobham and Sumner 2013).

${ }^{22}$ In order to study the statistical significance of the computed indexes, we used the Stata commands "digini" and "dientropy" contained in the DASP package (Abdelkrim and Duclos 2007). The Gini and the Theil index computed for the case when the HPI is used as deflator are also statistically different from the 2002/03 baseline at national level.
} 


\section{References}

Abdelkrim, A., Duclos, J.: DASP: Distributive Analysis Stata Package. PEP, World Bank, UNDP and Université Laval. (2007)

Amble, N., Stewart, K.: Experimental price index for elderly consumers. Mon. Labor Rev. 117(5), 11-16 (1994)

Arndt, C., Benfica, R., Maximiano, N., Nucifora, A., Thurlow, J.: Higher fuel and food prices: impacts and responses for Mozambique. Agric. Econ. 39(s1), 497-511 (2008)

Arndt, C., Hussain, M.A., Jones, E.S., Nhate, V., Tarp, F., Thurlow, J.: Explaining the evolution of poverty: the case of Mozambique. Am. J. Agric. Econ. 94(4), 854-872 (2012)

Arndt, C., Simler, K.R.: Estimating UtilityConsistent Poverty Lines with Applications to Egypt and Mozambique. Econ. Dev. Cult. Chang. 58(3), 449-474 (2010)

Cage, R.A., Garner, T.I., Ruiz-Castillo, J.: Constructing household specific consumer price indexes: an analysis of different techniques and methods. Bureau of Labor Statistics Working Paper 354, U.S. Department of Labor, Washington, D.C. (2002)

Cirera, X., Arndt, C.: Measuring the impact of road rehabilitation on spatial market efficiency in maize markets in Mozambique. Agric. Econ. 39(1), 17-28 (2008)

Cobham, A., Sumner, A.: Is it all about the tails? The Palma measure of income inequality. CGDEV Working Paper 343, Center for Global Development, Washington, D.C (2013)

Crawford, I., Smith, Z.: Distributional aspects of inflation. IFS Commentary 90, Institute for Fiscal Studies, London, UK (2002)

Dashwood, H.S.: Inequality, leadership, and the crisis in Zimbabwe. Int. J. 57(2), 209-226 (2002)

Deaton, A.: Getting prices right: what should be done. J. Econ. Perspect. 12(1), 37-46 (1998)

Dillon, B.M., Barrett, C.B.: The impact of world oil price shocks on maize prices in East Africa. University of Melbourne, Melbourne (2013)

Garner, T.I., Johnson, D.S., Kokoski, M.F.: An experimental consumer price index for the poor. Mon. Labor Rev. 119(9), 32-42 (1996)

Gasparini, L., Cruces, G., Tornarolli, L.: Recent trends in income inequality in Latin America. Economía 11(2), 147-201 (2011)

Günther, I., Grimm, M.: Measuring pro-poor growth when relative prices shift. J. Dev. Econ. 82, 245-256 (2007)

Hagemann, R.P.: The variability of inflation rates across household types. J. Money, Credit Bank. 14(4), 494510 (1982)

Hanlon, J.: Mozambique: The panic and rage of the poor. Rev. Afr. Polit. Econ. 36(119), 125-130 (2009)

IMF: World Economic Outlook. International Monetary Fund, Washington, D.C (2013)

INE: Categorias de Dados e Indicadores Sector Real. Instituto Nacional de Estatística, Maputo, Mozambique. Available at: http://www.ine.gov.mz/pt/ResourceCenter (2002)

INE: Inquérito sobre orçamento familiar, 2008/09 - Quadros basicos. Instituto Nacional de Estatística, Maputo, Mozambique (2010)

Leicester, A., O'Dea, C., Oldfield, Z.: The inflation experience of older households. IFS Commentary 106. Institute for Fiscal Studies, London, UK (2008)

Manjengwa, J., Feresu, S., Chimhowu, A. (eds.): Understanding poverty, promoting wellbeing and sustainable development. Institute of Environmental Studies, Harare, Zimbabwe (2012)

Milanovic, B.: A simple way to calculate the Gini coefficient, and some implications. Econ. Lett. 56(1), 4549 (1997)

MPF: Poverty and well-being in Mozambique: the second national assessment (2002-2003). National Directorate of Planning and Budget, Ministry of Planning and Finance, Economic Research Bureau, Ministry of Planning and Finance, International Food Policy Research Institute, Purdue University, Maputo, Mozambique (2004)

MPD/DNEAP: Poverty and well-being in Mozambique: the third national assessment. National Directorate of Studies and Policy Analysis, Ministry of Planning and Development, Maputo, Mozambique (2010)

Muellbauer, J.: Prices and inequality: the United Kingdom experience. Econ. J. 84, 32-55 (1974)

OECD. Stat Extract, http://stats.oecd.org/Index.aspx?DatasetCode=IDD. Accessed on October, 22nd (2014)

Ogwang, T.: A convenient method of computing the Gini index and its standard error. Oxf. Bullet. Econ. Stat. 62(1), 123-129 (2000)

Oosthuizen, M.: Inflation inequality in South Africa. DPRU Working Paper 13/158, Development Policy Research Unit. University of Cape Town, Cape Town (2013)

Palma, J.G.: Homogeneous middles vs. heterogeneous tails, and the end of the 'inverted U': It's all about the share of the rich. Dev. Chang. 42(1), 87-153 (2011) 
Ravallion, M., Bidani, B.: How robust is a poverty profile? World Bank Econ. Rev. 8(1), 75-102 (1994)

Schultze, C.L., Mackie, C.: At What Price? Conceptualizing and Measuring Cost-of-Living and Price Indexes. National Academy Press, Washington D.C. (2002)

Ssewanyana, N.S., Okidi, A.J., Angemi, D., Barungi, V.: Understanding the determinants of income inequality in Uganda. CSAE WPS/2004-29. Centre for the Study of African Economies, Oxford, UK (2004)

Ssewanyana, S.N., Kasirye, I.: Poverty and Inequality Dynamics in Uganda: Insights from the National Panel Surveys 2005/06 and 2009/10. EPRC Research Series 94. Economic Policy Research Centre, Kampala, Uganda (2012)

Tarp, F., Simler, K., Matusse, C., Heltberg, R., Dava, G.: The robustness of poverty profiles reconsidered. Econ. Dev. Cult. Chang. 51(1), 77-108 (2002)

Tostão, E., Brorsen, B.W.: Spatial price efficiency in Mozambique's post-reform maize markets. Agric. Econ. 33(2), 205-214 (2005)

UNU-WIDER: World Income Inequality Database (WIID3.0b). September 2014, UNU-WIDER, Helsinki (2014)

World Bank: Poverty trends in Uganda: who gained and who was left behind?. Inclusive growth policy note 1. World Bank, Washington, DC (2012) 